\title{
Yanılsamanın Akla Yatkınlığı: Alternatif Olanaklar İlkesi, Özgür İrade ve Ahlaki Sorumluluk
}

\section{[The Plausibility of Illusion: The Principle of Alternate Possibilities, Free Will, and Moral Responsibility]}

\author{
Kadir KÜTÜKOĞLU * \\ Muğla Sıtkı Koçman University
}

Received: 16.03.2021 / Accepted: 29.06.2021 DOI: $10.51404 /$ metazihin. 898110

\begin{abstract}
The principle of alternate possibilities (it may also be called the "PAP") is often used as the first premise in a core argument to prove that the incompatibilist accounts of free will and the ability to do otherwise. And what that means is that "An agent is morally responsible for what he/she has done, only if he/she could have done otherwise." In counter-response to this argument, Harry Frankfurt has issued an article in 1969. The way he came up with his conclusions were based on various counterfactual thought experiments. In this way, he was going to show how the principle of alternate possibilities can be falsified. The paper in question contained the following striking thoughts: (1) Free will does not entail (imply) alternate possibilities. (2) An agent can be morally responsible for what he/she has done even though he/she could not have done otherwise. (3) Coercion does not exclude moral responsibility. This study first gives an analysis of the "PAP," then proposes that the version of compatibilism which Frankfurt defends requires a revised description.
\end{abstract}

Keywords: Harry Frankfurt, the principle of alternate possibilities, free will, the ability to do otherwise, causal determinism, compatibilism, incompatibilism, moral responsibility, coercion.

Öz: Alternatif olanaklar ilkesi (-ki "PAP" olarak da adlandırılabilmektedir), genellikle bağdaşmazcı özgür irade ve başka türlü yapma olanağı kavrayışlarını tanıtlamak amacıyla çekirdek bir argüman içerisinde birinci öncül olarak kullanılır. Bu ilke, "Kişi ancak başka türlü yapabilseydi eyleminden ahlaki anlamda sorumlu olurdu" anlamına gelir. Söz konusu bağdaşmazcı çekirdek argümana karşı-cevap üretmek için Harry Frankfurt, 1969'da bir makale yayınladı. Onun çıkarımlarını ortaya koyma

\footnotetext{
* Author Info: Ph.D. Student - Muğla Sitkı Koçman University, Institute of Social Sciences, Department of Philosophy, Kötekli, Menteşe-Muğla, TÜRKIYE.

E-mail: kadirkutukoglu@posta.mu.edu.tr / Orcid Id: https://orcid.org/0000-0003-4845-4688

To Cite This Paper: Kütükoğlu, K. (2021). “Yanılsamanın Akla Yatkınlığı: Alternatif Olanaklar İlkesi, Özgür İrade ve Ahlaki Sorumluluk." MetaZihin, 4(1): 31-51.
} 
biçimi birtakım karşı-olgusal düşünce deneylerine dayanıyordu. Bu sayede alternatif olanaklar ilkesinin nasıl çürütülebilir olduğunu gösterecekti. Söz konusu makale, sırasıyla şu dikkat çekici düşünceleri içeriyordu: (1) Özgür irade alternatif olanakları gerektirmez. (2) Kişi başka türlü yapma olanağından mahrum olsa bile eyleminden ahlaki anlamda sorumlu olabilir. (3) Zorlama ahlaki sorumluluğu dişlamaz. Bu çalışma ilkin, "PAP"ye ilişkin bir çözümleme sağlarken sonrasında Frankfurt'un taraf tuttuğu konum nezdinde bağdaşırcılığın gözden geçirilmiş bir tanımı gerektirdiği önerisinde bulunmaktadır.

Anahtar Kelimeler: Harry Frankfurt, alternatif olanaklar ilkesi, özgür irade, başka türlü yapma olanağı, nedensel belirlenimcilik, bağdaşırcılık, bağdaşmazcılık, ahlaki sorumluluk, zorlama.

\section{Giriş}

Harry Gordon Frankfurt, Alternate Possibilities and Moral Responsibility (1969) (APaMR) ${ }^{1}$ başlığıyla yayınlanan makalesinde, kişinin gerçekleştirmekten kaçınamayacağ 1 eylemlerden ötürü ahlaki anlamda sorumlu olup-olmadığına ilişkin birtakım düşünce deneyleri kurgular. Bu düşünce deneyleri, özgür irade (ÖI) ve nedensel belirlenimcilik $(C D)$ arasında dönmekte olan tartışmalarla ilintili son felsefi literatür içerisinde tetikleyici bir konumda yer almasından ötürü önemlidir. APaMR, yarattığı etki bakımından, Is Justified True Belief Knowledge? (1963) başlığıyla Edmund Gettier'nin yayımladığı makalenin tetiklediği literatüre benzer (Fischer, 2010: 318; Vihvelin, 2013: 93; van Inwagen, 1999: 343-344).

Frankfurt'u harekete geçiren, John Locke tarafından An Essay Concerning Human Understanding' de (1689) takdim edilen, kişinin başka türlü yapma olanağından mahrum olduğuna ilişkin örneği (Locke, 1999: 223) yeniden değerlendirmeye alma isteğidir (Fischer, 2010: 315). Böylece o, alternatif olanaklar ilkesinin (PAP) yanlışlanabileceğini veya revize edilebileceğini düşünmeye başlar.

\footnotetext{
${ }^{1}$ Metin içerisinde birden fazla kez kullanılan tamlamaların bir kısmı, ilk kullanımlarından sonra bölüm başlıkları ve doğrudan alıntılar hariç olmak üzere, parantez içlerinde belirtildikleri biçimlerde aşağıdaki kısaltmalarla karşılanacaktır:

APaMR: Alternate Possibilities and Moral Responsibility

$P A P:$ The Principle of Alternate Possibilities

KOÖ: Kilitli Oda Örneği

FnDD: Frankfurt'un Düşünce Deneyleri

FVKö: Frankfurt-Vari Karş1-örnekler

$B C ̧ A$ : Bağdaşmazcı Çekirdek Argüman

$S A$ : Sonuç Argümanı

$C D$ : Nedensel Belirlenimcilik

ÖI: Özgür İrade
} 
Locke'un verdiği örnekte kişinin, kendisine haber verilmeden kilitlendiği bir evde veya bir odada istemli olarak kalıp-kalmamış olduğu tartışılır. Bu örnek, Kilitli Oda Örneği (KOÖ) olarak adlandırılır ve aşağıdaki biçime uyarlanarak temsil edilebilir:

(1) Tarihi niteliği ve niceliği olan büyükçe bir evdesiniz. Peki, bu evin dış kapısının dışarıdan kilitli olduğunu ve dışarı çıkamayacağınızı biliyor musunuz? Evin odalarını geziyorsunuz. Odalardaki tarihi eserler sizde tarifi güç duygular uyandırıyor. Evde kalıp diğer odaları da görmeye karar verdiniz.

(2) Evde kalmak için verdiğiniz kararda özgürdünüz çünkü burada kalıp odaları dolaşmayı gerçekten istiyorsunuz. Hiçbir şey sizi bu eyleminizi gerçekleştirmekten alıkoyamaz. Öte yandan, başka türlü yapma olanağından mahrumsunuz. Evde kalmak, esasında size sunulmuş olan tek seçenektir.

KOÖ şunu gösterir: Kişi başka türlü yapamasa bile evde kalmak için vermiş olduğu istemli karar, onun ÖI'li olduğunu gösterir. ${ }^{2}$

KOÖ'nün, Frankfurt'un Düşünce Deneyleri'nin $(F n D D)$ ve Frankfurt-Vari Karş1örnekler'in (FVKö) prototipi olduğu söylenebilir (Fischer, 2008: 2).

\section{Frankfurt'un Düşünce Deneyleri ve Frankfurt-Vari Karşı-örnekler}

Felsefe tarihi boyunca birçok filozof, kavranması oldukça güç ancak olanaklı gözüken bir görevi gerçekleştirmesi ve mevcut problemin antropomorfik bir düzlemde tartışılabilmesi için cin türevi imgelem ürünlerine başvurmuştur. Felsefi cinlerin ilk örneklerinden birine Apology'de rastlanılır. Duruşmasında Sokrates, Tanrı'nın veya bir $\delta \alpha i ́ \mu \omega v^{\prime}$ un kendisine filozof olma görevi verdiğinden bahseder (Nietzsche, 2007[1889]:

\footnotetext{
2 ÖI kavramının bu metindeki tartışmalar nezdinde en doğru ele alınış biçiminin, bu kavramın bir hipernim, eş deyişle kapsayıcı bir kavram (umbrella-term) olduğunu düşünen John Martin Fischer'ın düşünceleriyle koşut olarak cisimleşeceği belirtilmelidir: "Söz konusu kavram, farklı filozoflarca farklı biçimlerde ele alınmakta ve kullanılmakta olsa da ben özgür iradenin, ahlaki sorumluluğu ve en nihayetinde kişi olma durumunu tek bir potada eritebilen bir tür özgürlüğü tanımlamak için kapsayıcı bir kavram olarak kullanılmasının en faydalı yönelim olduğunu düşünüyorum. (Bana göre), özgür irade kavramının muhtevası, detaylıca odaklanıldığında, karar verme özgürlüğü, eylem özgürlüğü ve özgürce harekete geçme gibi çeşitlilikleri barındırdığı gibi ahlaki övgü, suçlama, ceza ve ahlaki ödül ile öfke, kızgınlık, minnettarlık ve saygı gibi çeşitlilikleri barındıran ahlaki tutum kümesini de kapsamaktadır. Bazı filozoflar, özgürlük ve ahlaki sorumluluk arasında belirgin bir ayrım yapmazlar. Bu ayrım yapmama durumuna detaylica odaklandığımızdaysa söz konusu kimselerin, felsefelerinde ahlaki sorumluluk kavramına öncelik atfetme eğiliminde olduklarını görürüz. Yani bu kimselere göre, hangi türde olursa olsun özgürlük kavramına dönüş, ahlaki sorumluluk kavramına atfedilen önceliği takiben gerçekleşmektedir. Ayrıca, dönüşün sonradan yapıldığı böylesi bir özgürlük kavramının (ahlaki sorumluluk kavramının çözümlemesinden ayrı olarak) bağımsız bir içeriği de yoktur. (Dolayısıyla) bu tür bir yönelimi benimseyen filozoflar arasında ele alınmakta (ve kullanılmakta) olan böylesi bir özgürlük kavramı, ahlaki anlamda sorumlu olacak biçimde karar vermek veya harekete geçmekle ilgili her türden koşulu ifade eder" (Fischer, 2005: XXIII).
} 
163) ve bu nedenle bir inançsız olarak yargılanmaması gerektiğine vurgu yapar (Plato, 1997: 30e).

Yine aynı biçimde, Descartes'ın da Meditations on First Philosophy'nin (1637) bir bölümünde Sokrates'inkinden farklı bir felsefi cin kurguladığı fark edilir (Descartes, 2013: 44). Onun böyle bir cinden bahsetmiş olmasının nedeniyse kesin bilgiye ulaşma yolunda insanların, Tanrı tarafından aldatılabileceğini, kesin bilgiyi elde etmenin duyular aracılığıyla olanaksız kılınmış olabileceğini düşünmüş olmasıyla bağlantılıdır. Tabii ki bir Cizvit Papazı olan Descartes Tanrı'ya böylesine kötü nitelikler atfetmez. Bunun yerine o, Tanrı'nın kötü niteliklerini, insanları aldatmakla görevli olarak kurgulamış olduğu felsefi cinine yansıtır (s. 44-45). Çünkü aldatıcı Tanrı ve kötü niyetli cin argümanları epistemolojik anlamda birbirlerine eşdeğer olsalar da kötü niyetli cin argümanı, aldatıcı Tanrı argümanına kıyasla (Descartes'ın düşüncelerine koşut olarak) daha az saldırgan ve daha az tutarsızdır (Kenny, 1987: 35). Tüm bunlar, duyuların kesin bilgileri sağlama noktasında yetersiz olması dolayısıyla Descartes'ın iç gözleme dönmesini sağlar. Böylece o, cin duyularını aldatıyor olsa bile düşünceleri ve varlığı konusunda yanılmasının olanaksız olduğu bilgisine ulaşmaya çalışır.

$F n D D^{\prime}$ de kurgulanan cin ise kişiye açık olan alternatif eylem ve karar olanaklarını sınırlamak amacıyla müdahalelerde bulunmakta olan bir kontrolörlük görevi üstlenir. Bu felsefi imgelem ürününün ismi haricinde ne olduğu veya nasıl göründüğü belli değildir. FVKö' de farklı isimlerle karşılaşılsa da kişilere karşı-olgusal müdahalelerde bulunan cinin ismi genellikle Black'tir (Frankfurt, 1969: 835). ${ }^{3}$

FnDD, $P A P^{\prime}$ nin karşı-örneklerini sağlar. Çok yönlülüklerinden ve gitgide kompleks bir hal almaya başlayan senaryolarından ötürü, son felsefi literatürde FVKö olarak

3 John Martin Fischer, APaMR'deki FnDD'nin güncel uyarlamaları olan FVKö'nün birkaçını şöyle örneklendirir: “(1) Yardımsever ama yaşlı bir beyin cerrahı olan Black, Demokratların Beyaz Saray'ı alma şanslarının nihayet yüksek olmasını ummaya cüret ettiği için, farklı bir felsefi tartışmaya katılmak üzere emeklilik hayalinden vazgeçmek durumunda kalmıştır (Sonuçta muhterem akıl hocamız Black olmadan bu düşünce deneylerinin hali nice olurdu? Belki de yerine Noire'nın geçmesi daha doğrudur, kim bilir?). Bu muhterem akıl hocamız, Jones'un beynine, onun bütün eylemlerinin dökümünü tutmasının yanı sıra bunları kontrol etmesini de sağlayan bir çip yerleştirmiştir. Black, bu çipi kontrol etmek amacıyla oldukça güçlü bir bilgisayar dahi programlamıştır. Ne de olsa böylece, Jones'un oy verme eylemini izleyebilecektir. Jones, McCain'e (veya diyelim ki Obama dışındaki herhangi birine) oy verme eğilimi gösterseydi, programlanmış bilgisayar, Jones'un Obama'ya oy vermesini garanti etmek adına ona müdahale edebilecek olurdu. Ĕ̆er ki Jones, kendi iradesiyle Obama'ya oy vermek için karar verirse (Black gibi yeni modaya ayak uydurmaya çalışan bir ihtiyarın kararı da bu yöndedir), programlanmış bilgisayar kendisine hiçbir müdahalede bulunmazdı ancak Jones'un kafasındaki düşünceleri izlemeyi de sürdürürdü. (2) Şimdi de şöyle bir varsayımı düşünelim. Diyelim ki Black, Jones'un beynine bir çip yerleştirmedi. Ayrıca tıpkı ilk durumdaki gibi Jones, Obama'ya kendi iradesiyle oy vermeye karar verdi. Bu varsayıma yoğunlaştığımızda, ilk bakışta şu sonuca varmamız olanaklıdır; Jones Obama'ya oy vermeye karar verdiğinden ve bunu gerçekleştirdiğinden ötürü ahlaki anlamda sorumlu olsa da başka türlü karar verme ve başka türlü yapma olanağından her halükârda mahrumdur" (Fischer, 2010: 316). 
adlandırılırlar ve mantıksal karşı-örneklerle de desteklenmeye devam ederler (Timpe, 2013: 77).

FnDD'deki senaryolar oldukça esnek bir yapıda tasarlanmıştır (Frankfurt, 1969: 836). Frankfurt'un ya kötü niyetli bir sinirbilimci ya da kararlara müdahale eden bir cin

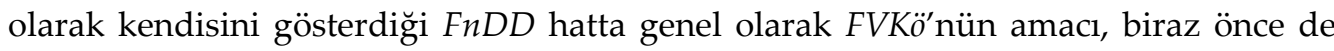
söylenmiş olduğu gibi $P A P^{\prime}$ nin yanlış olduğunu gerekçelendirmek veya en azından söz konusu ilkede bir revizyona gereksinim duyulduğunu göstermektir (s. 830, 838).

FnDD açısından konuşulacak olursa Frankfurt'u $A P a M R$ 'de böyle hareket etmeye yönlendiren düşünce şudur:

Esasında, alternatif olanaklar ilkesi yanlış bir ilkedir. Kişi, başka türlü yapma olanağından mahrum olsa bile yaptığından ahlaki anlamda sorumlu olabilir. Dolayısıyla, ilkenin akla yatkınlığı bir yanılsamadır, keza ilgili ahlaki görüngüler, bu yanılsama sayesinde daha keskin bir odak noktasına çekilerek görüş alanından tamamıyla uzaklaştırılabilirler. (Frankfurt, 1969: 829)

\section{Bağdaşmazcı Çekirdek Argüman ve Peter van Inwagen'in Sonuç Argümanı}

Öncelikle, Frankfurt'un klasik bağdaşırcı ${ }^{4}$ olmadığı bilinmelidir. O, zayıf bağdaşırcılığın ${ }^{5}$ tarafını tutar (Campbell, 1997: 319).

Bağdaşmazcı Çekirdek Argüman ${ }^{6}(B C ̧ A)$, iki öncül ve bir sonuç önermesi biçiminde aşağıdaki gibi numaralandırılarak temsil edilebilir bir argümandır:

(1) Öİ, başka türlü yapma olanağı gerektirir.

(2) $C D$ doğruysa kimsenin başka türlü yapma olanağı yoktur.

(3) Öyleyse Öİ, CD’nin yanlışlanmasını gerektirir (Timpe, 2013: 69).

$B C ̧ A$, mantıksal olarak geçerli bir argümandır ve argümandan türetilen çıkarım bağdaşırcılığın yanlış olduğunu ima eder.

\footnotetext{
${ }^{4}$ Klasik bağdaşırcılık (aşırı bağdaşırcılık olarak da adlandııılmaktadır) şunları varsayar: (1) ÖI ve ahlaki sorumluluk için alternatif eylem olanakları gereklidir. (2) ÖI ve ahlaki sorumluluk, $C D$ ile bağdaşır (Campbell, 1997: 319).

${ }^{5}$ Zayıf bağdaşırcılık şunları varsayar: (1) Ahlaki sorumluluk, alternatif eylem olanaklarını gerektirmediği gibi, herhangi türde bir ÖI'yi de gerektirmez. (2) Ahlaki sorumluluk ve ahlaki sorumluluk için gerekli olan herhangi türde bir ÖII, CD ile bağdaşır (Campbell, 1997: 320).

${ }^{6}$ The Core Argument for Incompatibilism
} 
Diğer yandan, $B C ̧ A^{\prime}$ nın bir kıyas biçiminde olan popüler gösterimi Peter van Inwagen'e $(1975,1983,1989,2000)$ ait Sonuç Argümanıyla7 $(S A)$ sağlanabilir.

$B C ̧ A$ ile ilişkilendirilen $S A$ 'nın ilettiği anlamsa şudur: ' $C D$ doğruysa kimse $O ̈ I ' l i$ değildir'. Eş deyişle, ' $C D$ doğruysa geçmişin ve geleceğin olayları kimsenin gücünün dâhilinde değildir ve asla gücünün dâhilinde olmamıştır':

(1) Geçmişin olayları ve doğa yasaları kimsenin gücünün dâhilinde değildir.

(2) Geçmişin olaylarının ve doğa yasalarının, geleceğin olaylarını gerektirdiği kimsenin gücünün dâhilinde değildir (eş deyişle, $C D$ doğrudur).

(3) Öyleyse geleceğin olayları kimsenin gücünün dâhilinde değildir (Vihvelin, 2018).

$S A^{\prime}$ 'nın geçerliliği, standart modal mantık aracılığıyla gösterilebilir. Buna göre, ' $\mathrm{N}$ ' modal bir işlemci, $p$ herhangi bir önerme olmak üzere; $\mathrm{N} p=$ df " $p$ doğrudur ve $p$ 'nin doğruluğunu yanlışlamak kimsenin gücü dahilinde değildir" (van Inwagen, 1989: 404405; 2000: 2) anlamına gelir ve $S A$, iki çıkarım kuralına dayalı bir argüman biçiminde aşağıda verildiği gibi cisimleşmeye başlar:

( $\alpha) \square p \vdash \mathrm{N} p$;

(ß) $\mathrm{N} p, \mathrm{~N}(p \rightarrow q) \vdash \mathrm{N} q$ (çıkarım kuralı modal Modus Ponens).$^{8}$

' $\square$ ' sembolü modal mantıkta sıkı gerektirme (strict implication) işlemcisidir ve ' $\square p^{\prime}$, , $p$ ' olası tüm dünyalarda zorunlu olarak doğrudur' (van Inwagen, 2000: 2; 1989: 405) veya “öyle bir önerme vardır ki bu önerme ancak ve ancak mantıksal olarak olası tüm dünyalarda doğruysa mantıksal olarak zorunludur" (Campbell, 2016: 155) olarak okunur. Her iki çıkarım kuralında yer alan ' $\vdash$ ' (turnstile) sembolü, verili formülün ilgili sistemin kanıtlanabilir bir teoremi (veya kantlanacak bir önermesi) olduğu anlamını ileten ikili gerektirme bağıntısını temsil eder ve $(\alpha)$ çıkarım kuralı, ‘ $\square p^{\prime}$ den $\mathrm{N} p$ çıkarsanabilir' veya ' $\mathrm{N} p, \square p$ 'den türetilebilir' olarak okunur. ( $\beta$ ) çıkarım kuralıysa ' $\mathrm{N} p$ ve $\mathrm{N}(p \rightarrow q)$ 'dan $\mathrm{N} q$ çıkarsanabilir' veya ' $\mathrm{N} q$, $\mathrm{N} p$ ve $\mathrm{N}(p \rightarrow q)$ 'dan türetilebilir' olarak okunur.

7 The Consequence Argument

$8 \square(\phi \rightarrow \psi), \square \phi \vdash \square \psi:$
(1) $\square(\phi \rightarrow \psi)$
(2) $\square \phi$
(öncül 1)
(3) $\square(\phi \rightarrow \psi) \rightarrow(\square \phi \rightarrow \square \psi)$
(öncül 2)
(4) $\square \phi \rightarrow \square \psi$
(S5'ten aksiyom $K)$
(5) $\square \psi$
(1, 3, çıkarım kuralı modal Modus Ponens)
(2, 4, çıkarım kuralı modal Modus Ponens) 
İlkin, $S A^{\prime}$ nın söylem kutusunda, uzak geçmişteki herhangi bir zaman diliminde evrenin eksiksiz bir tanımı olarak po, uzak geçmişteki herhangi bir zaman diliminde evrende içkin olan doğa yasalarının eksiksiz bir açıklaması olarak $l$ ve geçmişteki herhangi bir zaman diliminde herhangi bir kişinin gerçekleştirmiş olduğu eylemi tanımlar olarak $p$ önermelerinin içerildiği belirtilir. Sonrasındaysa argümanın muhtevasını oluşturan söylem kutusunda yer alan önermeler vasıtasıyla $S A^{\prime}$ nın art alanında yatan düşüncenin amacı, içerikte varsayılan kişinin gerçekleştirdiği $p$ eyleminin ancak $\mathrm{N} p$ 'nin yanlış olması durumunda bu kişinin gücünün dâhilinde olduğunun ${ }^{9}$ anlaşılması üzerine bütünlük kazanır (van Inwagen, 1989: 404-406; 2000: 2; List, 2019: 254-255; Gustafsson, 2017: 706).

$S A^{\prime}$ 'nı standart modal mantıktaki (veya $S 5^{\prime}$ teki) gösterimi aşağıdaki biçimde verilebilir:

(1) $\square\left(\left(p_{0} \wedge l\right) \rightarrow p\right) \quad\left(C D^{\prime}\right.$ 'nin tanımı gereği biçimsel gösterimi $)$

(2) $\square\left(p_{0} \rightarrow(l \rightarrow p)\right) \quad\left(1, S L^{\prime}\right.$ den yerine koyma kuralı Exportation $)$

(3) $\mathrm{N}\left(p_{0} \rightarrow(l \rightarrow p)\right) \quad(2$, çıkarım kuralı $(\alpha))$

(4) $\mathrm{N} p_{0} \quad$ (Geçmişin Değişmezliği İlkesi ${ }^{10}$ )

(5) $\mathrm{N}(l \rightarrow p) \quad(3,4$, çıkarım kuralı $(\beta))$

(6) $\mathrm{N} l$

(Doğa Yasalarının Sabitliği İlkesi ${ }^{11}$ )

(7) $\mathrm{Np}$

(5, 6, çıkarım kuralı ( $\beta)$ ) (van Inwagen, 1989: 405; 2000: 2)

$S A^{\prime}$ nın bu gösteriminde $C D, N p^{\prime}$ yi gerektirir. Bu gerektirme, ayrıca, $p$ ile tanımlanan, herhangi bir kişinin geçmişte gerçekleştirdiği eylemin, bu kişinin gücünün dâhilinde olmadan gerçekleştiğinin zorunlu doğruluğunu da gerektirir. Çünkü $(\alpha)$ ve $(\beta)$ çıkarım kurallarının kabul edilmesi, $\mathrm{N} p_{0}$ ve $\mathrm{Nl}$ 'nin yanlışlanmasını gerektirir (List, 2019: 255) ki bu da saçmadır. Dolayısıyla $S A$, mantıksal olarak geçerli bir argümandır ve çıkarımı $C D$ 'nin, ÖI ile bağdaşık olmadığı anlamını ilettiğinden söz konusu argümanın çıkarımının $B C ̧ A^{\prime}$ nın çıkarımına eşdeğer olduğu söylenebilir. ${ }^{12}$

$B C ̧ A, C D$ ve ahlaki sorumluluğun bağdaşmaz olduğunu iddia etmenin temel dayanaklarından biridir (Harrison, 2006: 399). Bu yüzden, klasik ve/veya zayıf

\footnotetext{
${ }^{9}$ Gücü dâhilinde olmak durumu, $p$ önermesinin yanlışlanmasını kesinleştirebilmeyi gerektirir. Bu durum da $C D^{\prime}$ nin tanımı gereği biçimsel gösteriminin mantıksal eşdeğeriyle ( $S L^{\prime}$ den yerine koyma kuralı Transposition) şu biçimde gösterilebilir: $\square\left(\left(p_{0} \wedge l\right) \rightarrow p\right)=\neg p \rightarrow \neg\left(p_{0} \wedge l\right)$.

${ }^{10}$ The Principle of the Fixity of the Past

${ }^{11}$ The Principle of the Fixity of the Laws

${ }^{12}$ Bu nedenle, bu metnin bundan sonraki kısımlarında, $B C ̧ A$ ile kastedilen, $S A^{\prime} y ı$ da kapsayacaktır.
} 
bağdaşırcılık açısından $B C ̧ A^{\prime}$ yı reddetmenin tek yolu, muhtevasını oluşturan öncüllerden en az birinin doğruluğunu reddetmekten geçer (Timpe, 2013: 83).

Buna örnekse şudur: Eğer (1) numaralı öncülün doğruluğu reddedilmek isteniyorsa ÖI'́nin başka türlü yapabilmeyi gerektirmemesi gerekir. Yani kişi, alternatif olanakları olmadan da ÖI'li olabilmelidir. Çünkü $B C ̧ A^{\prime}$ nın (2) numaralı öncülü nezdinde, ÖI'nin başka türlü yapabilmeyi gerektirmemesi, $C D^{\prime}$ nin tanımıyla, bu tanım doğru kabul ediğinden, mantıksal olarak bağdaşık olmalıdır.

Öİ, $P A P^{\prime}$ de içkin olan başka türlü yapma olanağını gerektirir. $B C ̧ A^{\prime}$ nın (1) numaralı öncülü $P A P$ olarak adlandırılır ve ahlaki sorumluluk ile $C D^{\prime}$ nin bağdaşmaz olduğuna yönelik etkili olan bir argümanın en önemli parçasını oluşturur. Ancak $P A P$, önemli olduğu kadar söz konusu argümanın en zayıf parçası olarak da görülür (Copp, 1997: 441; 2006[2003]: 251). ${ }^{13}$

Çağdaş felsefe tarihi içerisinde, $P A P^{\prime}$ nin ilettiği koşulun yani $B C ̧ A^{\prime}$ nın (1) numaralı öncülünün, Öİ problemiyle ilgili tartışmalarda neredeyse müşterek kabul gördüğü bir zaman diliminin varlığının göz ardı edilemez olduğu bilinmelidir. Keza bu ifade, van Inwagen gibi bazı filozofların dahi, ÖI'yi alternatif olanakların koşulu olarak tanımlamalarının nedenini açıklamada yardımcı olmaktadır (Timpe, 2013: 70).

Ancak Frankfurt, $A P a M R$ ile $B C ̧ A^{\prime}$ ya farklı bir perspektiften nasıl yaklaşılabileceğini göstererek söz konusu problemle ilgili tartışmaların seyrini değiştirebilmenin önünü açar:

Benim alternatif olanaklar ilkesi olarak adlandıracağım bir ilke, özgür irade sorununa ilişkin güncel soruşturmaların neredeyse tamamında baskın bir roldedir. Bu ilkenin anlamı, kabaca, bir kişinin yaptığından ancak başka türlü yapabilmiş olması durumunda ahlaki anlamda sorumlu olacağın belirtir. Detaylı anlamıysa özellikle bu ilkeyi benimseyenler arasında dönmekte olan ahlaki sorumluluk ve (nedensel) belirlenimciliğin bağdaşmaz olup-olmadığı konusunda kimin hangi tarafı tuttuğunun tam olarak kestirilemediği bir tartışmaya ilişkindir. Hâlbuki gerçekte görünen, tartı̧̧mada isimleri dönmekte olan kişilerin hiçbirinin, alternatif olanaklar ilkesinin (ilkenin kendisinin istenilen kelimelerle karşılanmasının benim açımdan bir mahsuru yoktur) doğru olduğunu ne inkâr etmeye ne de sorgulamaya meyilli olduklarıdır. Söz konusu ilkenin kendisi o kadar inandırıcı gelmiştir ki bu isimlere, içlerinden bazıları bunu a priori bir doğru olarak nitelendirmekte bile bir beis görmemişlerdir. Özgür irade veya ahlaki sorumluluğa dair kendi paylarına yaptıkları açıklamaları kökten anlaşmazlık içinde olan kimseler, bu metinde, muhalif tutumlarını aşikâr bir biçimde karlı bir alışverişe

${ }^{13} P A P, B C ̧ A^{\prime}$ nın bir öncülüdür. Dolayısıyla $P A P, B C ̧ A$ içinde ahlaki sorumluluğun $C D$ ile bağdaşmaz olduğunu gösterirken söz konusu argümanda, $C D^{\prime}$ nin başka türlü yapma olanağıyla bağdaşmaz olduğunu gösteren ek bir öncülün bulunmasını gerektirir (Copp, 2006[2003]: 251). 
çevirebilecekleri, oldukça sağlam ve uygun bir müşterek zemin bulacaklardır (Frankfurt, 1969: 829).

Frankfurt'un ilettiği argümanların sonuçlarının hafife alınması güçtür (McKenna, 2010: 436). Çünkü $A P a M R^{\prime}$ de verdiği karşı-örneklerle Frankfurt, $P A P^{\prime}$ nin reddedilebilmesini gerekçelendirmiş olduğundan $B C ̧ A$ nezdindeki tartışmaların seyrini kayda değer ölçüde değiştirebilmeyi de başarır. Çağdaş Öİ tartışmalarının içeriğinden yardım alarak bu düşünceyi doğrulayabilmenin olanaklı olduğu söylenebilir (Timpe, 2013: 71).

\subsection{Frankfurt'un Alternatif Olanaklar İlkesi Tanımı Tam Olarak Nasıl} Anlaşılmalıdır?

Frankfurt'un $A P a M R^{\prime}$ de verdiği $P A P^{\prime}$ nin tanımında kullanılan Could Have kalıbı, kişinin geçmişteki bir eylemi istese gerçekleştirebilme olanağına sahip olduğunu belirtir. Bununla birlikte söz konusu kalıp, Might Have kalıbıyla karıştırılmamalıdır. Çünkü Might Have kalıbı da bir olanak bildiriyor olmasına rağmen bu olanak bir olasılığa bağlıdır. ${ }^{14}$

Might Have kalıbının kullanıldığı, rastlantısal oluşturulmuş şu örnek-kurgusal İngilizce tümcelere odaklanılırsa konuşulan şimdiki zamanda söz konusu edilen, geçmişte meydana gelmesi istenen olayların olasılıklarının, geçmişte meydana gelmeyen başka olayların koşulunu ifade etme fonksiyonlarında oldukları açıça fark edilebilir: If I had said to my pymgmy marmosets not to panic, they might not have panicked [İpek maymunlarıma paniğe kapılmamalarını tembihleseydim, paniğe kapılmaları gerekmeyebilirdi] ve If I had fed enough of my sea cucumbers, they might not have died [Denizhıyarlarımı yeterince besleseydim, ölmeleri gerekmeyebilirdi]. Hâlbuki Was (Were) Able To kalıbının olanaklılı̆̆ı, bir olasılığa bağlı değildir. Dolayısıyla Was (Were) Able To kalıbının, Türkçede fiillere gelerek, tümceye şart, istek veya dilek anlamları katan dilek-şart kipinin hikâyesiyle koşut olduğunu söylemenin şimdilik bir mahsuru olmadığı belirtilebilir. Keza bu koşutluk, önce Türkçe olarak verilip, sonrasında İngilizcelerine çevrilerek, biraz önce verilen örnek-kurgusal tümcelerde yapılacak uyarlamalar nezdinde karşılaştırmalı bir biçimde imlenebilir niteliktedir: 'İpek maymunlarımı yanımda götürseydim, paniğe kapılmazlardı' [If I had took them my pymgmy marmosets on my side, they were able not to panic] ve 'Yem almak için yeterli param

\footnotetext{
${ }^{14} C D$ ile ilişkisi nezdinde $P A P$, mantıksal olarak doğru kabul edilirse ahlaki sorumluluk ve $C D$ bağdaşık olamaz. Çünkü $C D$, mantıksal olarak doğru kabul edilirse söz konusu edilecek olan tek bir gelecek olmalıdır. Dolayısıyla $P A P^{\prime}$ nin tanımında kullanılan gramer, $C D$ doğruysa kişinin gerçekte yani söz konusu edilecek tek gelecekte, yapacağını başka türlü yapmasının olanaklı olmamasıyla ilişkisi nezdindeki mantıksal doğruluk durumlarıyla koşutluğu ifade etmelidir.
} 
olsaydı, denizhıyarlarım açlıktan ölmezdi' [If I had enough money to buy food, my sea cucumbers were not able to die].

Sonuç olarak Frankfurt'un $P A P$ tanımı nezdinde düşünmek isteniyorsa en başında şuna benzer ayrımlara dikkat etmenin yerinde olacağının altı çizilmelidir:

(1) Could Have, Might Have kalıbının ilettiği anlamla bağdaşık değildir. Bu yüzden söz konusu kalıbın, Be fiilinin geçmiş zaman kipi içerisinde, başlanmış ve tamamlanmış bir eylemi kastetmek amacıyla kullanılan Was (Were) Able To kalıbına koşut olarak kullanıldığı not edilmelidir. Dahası Was (Were) Able To kalıbı da yine bir örnek üzerinden açıklanacak olursa: I was able to fix my particle accelerator, now it's fine [Parçacık hızlandırıcımı tamir edebildim ve şu an bir sorunu yok] tümcesinde içkin olan bir zamansal ve anlamsal notasyon biçimiyle eşleniktir. Çünkü verilen örnekte bahsi geçmekte olan parçacık hızlandırıcısı, konuşulan zamandan bir süre önce tamir edilmiş olduğundan söz konusu kalıbın kullanımı, geçmişte başlanmış ve (bütünüyle) tamamlanmış bir eylemin kendisini imlemektedir.

(2) Could Have kalıbının iki anlamlılığı yani Might Have ve Was (Were) Able To kalıp belirsizliği, PAP tartışmalarında hatta genel olarak ÖI problemi tartışmalarında muazzam ölçüde kafa karışıklıkları yaratmıştır. Karşılaştırılabilmesi için Türkçesi ve İngilizcesiyle birlikte verilecek olursa van Inwagen, bu belirsizliğin John Langshaw Austin'in (1979[1956]) örneklerinden uyarlanan şu örnek tümcelerle biraz olsun giderilebilir olabileceğini ifade eder:

$\mathrm{Bu}$ sabah ipliğimi pazara çıkarabilirdin. Allah aşkına, basına demeç verirken ne söylediğine dikkat et [You could have exposed me this morning. For God's sake, watch what you're saying when you talk to the press].

Bu sabah ipliğimi pazara çıarabilirdin. Bunu yapmadığın için sana minnettar olduğumu bilmeni istiyorum [You could have exposed me this morning. I want you to know that I'm grateful you didn't] (van Inwagen, 1999: 344).

Frankfurt'un, $A P a M R^{\prime}$ de reddedilmesi veya bir revize edilmesi gerektiğini öne sürdüğü $P A P^{\prime}$ nin genel tanımı tam olarak şöyledir: “Kişi ancak başka türlü yapabilseydi, eyleminden ahlaki anlamda sorumlu olurdu" (Frankfurt, 1969: 829). Dolayısıyla üst paragraflarda verilen gramatik nüanslar ve Frankfurt'un $P A P$ tanımını ele alış biçimi nezdinde, $B C ̧ A^{\prime}$ nın da aşağıda verildiği gibi düşünülmesi şimdilik daha doğru olacaktır:

(1) Kişi, ancak başka türlü yapabilseydi, eyleminden ahlaki anlamda sorumlu olurdu.

(2) Kişi, ancak $C D$ yanlış olsaydı, başka türlü yapabilirdi. 
(3) Öyleyse kişi, ancak $C D$ yanlış olsaydı, eyleminden ahlaki anlamda sorumlu olurdu.

\section{Alternatif Olanaklar İlkesi ve Reddedilmesinin Gerekçelendirilmesi: Birtakım Senaryolar Kurgulamak}

Şöyle bir örnek düşünelim. Bir kişi, tahammül sınırlarını zorlayacak olan bir cezayla(...) inandırıcı bir biçimde tehdit edilmiş olsun ve bu kişinin(...) kendisinden yapılması istenen bir eylemi gerçekleştirdiğini varsayalım. Tehdit edilen bu kişinin, söz konusu eylemi yapmaya zorlandığını dolayısıyla başka türlü yapamayacağını ve yapmaya zorlandığı eylemi gerçekleştirdiği için ahlaki anlamda sorumlu olmadığını düşünmemizi haklı kılacak birtakım detayları zihnimizde canlandırmamız olanaklıdır. Ancak bu tür durumlarda, tehdit edilen kişinin yaptığından ahlaki anlamda sorumlu olmadığı yargısını garanti eden şey nedir? (Frankfurt, 1969: 831).

Önceki bölümlerde tekrarlandığı gibi, $F n D D$ hatta $F V K \ddot{\prime}$ ye ilişkin senaryolar, en temelde, $P A P^{\prime}$ nin yanlış bir ilke olduğu, dolayısıyla reddedilmesi gerektiği, öyle olmasa bile en azından revize edilmesi gerektiği üzerine kuruludur. Bu bölümde $A P a M R$ 'de kurgulanmış olan $F n D D^{\prime}$ deki senaryolara odaklanılacaktır.

Frankfurt, $A P a M R^{\prime}$ deki amacını gerçekleştirmek için kurguladığı düşünce deneylerinin söylem kutusunda ilkin, eyleminden ahlaki anlamda sorumlu ancak söz konusu eylemi başka türlü yapma olanağından da mahrum olarak gerçekleştiren Jones isimli bir kişi ve bu kişiye müdahalelerde bulunan Black isimli felsefi bir cin tanımlar. Sonrasındaysa $P A P^{\prime}$ yi yanlışlamak için hamlelerde bulunarak $B C ̧ A^{\prime}$ yı çürütmeye çalışır.

$A P a M R$ içindeki $F n D D^{\prime}$ de verilen karşı-olgusal senaryolar, birebir alıntılar baz alınarak sırasıyla şöyle özetlenebilir:

Tehdit, Jonesı'un eylemini gerçekleştirmesinde onun iradesini etkileyen bir kuvvet uygulamadi(...) Jonesı (...) sonrasında başına ne gelecek olursa olsun yapmaya karar verdiği her şeyi her halükârda yapar (çünkü pek aklıselim biri değildir)(...) Tehdidin Jonesı için hiçbir önemi yoktu. $\mathrm{O}$, sanki hiç tehdit edilmemiş gibi ne tehdide ne de tehdit edene aldırarak hareket etti. Eğer ki işler bizim şu anda varsaydı̆̆ımız gibi ilerlediyse söz konusu durumda hiçbir zorlama emaresi yoktur. Çünkü tehdit, Jonesı'u yaptı̆̆ı şeyi yapmaya yönlendirmede en ufak bir etkiye tekabül etmedi. Bununla birlikte, onu yaptığ1 şeyi başka türlü yapma mahrum bırakmak da yeterli değildi: Jonesı'un eylemini gerçekleştirmeden önceki kararı başka bir şey yapmak üzerine olsaydı, tehdit, yine aynı biçimde onda en ufak bir cayma uyandırmazdı(...) Jonesı' un tehdit edilmiş olması, kendi iradesiyle yaptığının tersini yapması durumunda, eylemi için üstleneceği ahlaki sorumluluğu azaltmaz (Frankfurt, 1969: 831-832).

Burada aktarılanlardan hareketle, birinci senaryo aşağıdaki biçimde çözümlenebilir:

(1) Jonesı $A$ eylemini gerçekleştirmeye karar verir. 
(2) Jones1 aklıselim biri değildir. Aklına esen her eylemi her halükârda gerçekleştirir, hiçbir şey onu verdiği karardan vazgeçiremez (veya caydıramaz). Dolayısıyla başka türlü yapmaya karar vermesi durumunda, zorlama faktörü devreye girse de Jonesı tehdide karşı direnç gösterecektir.

(3) Jonesı $A$ eylemini gerçekleştirmesi için tehdit edilir.

(4) Tehdit, Jonesı'i A eylemini gerçekleştirme noktasında hareket geçirmemiştir.

Birinci senaryoda, Jonesı, gerçekleştirmiş olduğu eyleminden ahlaki anlamda sorumludur. Yalnız burada gözden kaçırılmaması gereken bir nüans vardır. Bu da Jones' 1 in karakteridir. Çünkü sahip olduğu karakterin bir özelliği gereği o, her türden tehdide karşı dirençlidir. Dolayısıyla zorlama faktörü onu bu senaryonun varsayımı gereği etkilememektedir.

Bir diğer senaryoysa Jones'un tehdit vasıtasıyla eylemini gerçekleştirme noktasında zorlama faktörüne maruz kalacak olması üzerine kuruludur:

Jones2 öncesinde hangi kararı vermiş olursa olsun eylemini daha bir şevkle gerçekleştirirdi(...) Tehdit onu o denli derinden altüst ederdi ki(...) cezadan ziyadesiyle korktuğu için önceki kararını tamamıla unutur ve kendisinden talep edilen eylemi kuşkuya yer bırakmaksızın gerçekleştirirdi(...) Jones2, tehdidin kendisinden başka bir şey düşünmezdi ve salt korku onu yapmak istediği şeyi yapmaya yönlendirirdi. Jones2(...), kararından ötürü ahlaki anlamda sorumlu olsa bile(...) eyleminden ötürü ahlaki anlamda sorumlu değildir. Çünkü o, eylemini maruz kaldığı zorlamanın bir sonucu olarak gerçekleştirdi. Başta almış olduğu karar, onu, eylemini gerçekleştirmeye yönlendirmede hiçbir rol oynamadı. Bu nedenle onun ahlaki karakterini değerlendirmek için, başta vermiş olduğu karara bir rol atfetmek yersizdir (Frankfurt, 1969: 832).

Burada aktarılanlardan hareketle, ikinci senaryo aşağıdaki biçimde çözümlenebilir:

(1) Joness $A$ eylemini gerçekleştirmeye karar verir.

(2) Jones2 $A$ eylemini gerçekleştirmesi için tehdit edilir.

(3) Tehdit, Jones2'nin A eylemini gerçekleştirme noktasında, baştaki kararını tamamiyla unutmasına neden olmuştur.

(4) Tehdit, Jones2'yi $A$ eylemi gerçekleştirme noktasında harekete geçirmiştir.

Bu senaryoda, Joness zorlamadan etkilendiği için eyleminden ahlaki anlamda sorumlu değildir. Onun yalnızca, tehditten etkilendiği için ahlaki anlamda sorumlu olduğu söylenebilir. Çünkü ilk senaryoda görülebileceği üzere tehdit, Jonesı'i eylemini gerçekleştirme noktasında, karakterine ait bir özellik gereğince hiçbir biçimde etkilememiş olsa da Joneš' yi etkilemiştir. 
Son olarak, üçüncü senaryodaysa Jones, tehdit, eş deyişle, zorlama faktörüne maruz kalmayacaktır ancak bunun $A$ eylemini yapması durumunda geçerli olacağı belirtilmelidir:

Tehdit, her aklıselim insanı etkileyecek olduğu gibi Joness'u da etkilerdi(...) (Jones3) kendisinden talep edilen şeyi yapmasıyla çakışan bir karara varmış olsaydı, zorlamaya bütün kalbiyle boyun eğmek zorunda kalacak olurdu(...) Joness eylemini, tehdit edilmeden önce kendi iradesiyle vermiş olduğu karara göre gerçekleştirdi. Yani Jones3 eylemini gerçekleştirmesi için tehdit edilmedi; onu eylemini gerçekleştirmede harekete geçiren şey(...) (iradi olan) içsel motivasyonuydu. Ancak(...) tehdit, onu harekete geçmeye itmemiş olsa bile, Joness'un yeterli içsel motivasyonu sağlayamadığ ${ }^{\prime}$ durumda devreye girecekti, nihayetinde de Jones s söz konusu eylemi, her halükârda gerçekleştirmek zorunda kalacaktı (Frankfurt, 1969: 832).

Takip edilen bu pasaja göre üçüncü senaryo da aşağıdaki gibi çözümlenebilir:

(1) Joneš $A$ eylemini gerçekleştirmeye karar verir.

(2) Joness aklıselim biridir. Aklına esen her eylemi her halükârda gerçekleştiremez. Dolayısıyla başka türlü yapmaya karar vermesi durumunda zorlama faktörü devreye girecek ve Joness tehdide karşı direnç gösteremeyip buna bütün kalbiyle boyun eğmek zorunda kalacaktır.

(3) Joness' ün $A$ eylemini gerçekleştirmesi için tehdit edilmesine gerek kalmamıştır.

(4) Tehdit, Joness' $\mathbf{u} A$ eylemini gerçekleştirme noktasında harekete geçirmemiştir. Jonesz, A eylemini salt kendi gerekçelerine dayanarak gerçekleştirmiştir.

Üçüncü senaryo içerisinde, Joness eyleminden ahlaki anlamda sorumludur.

\subsection{Senaryolarda Yer Alan Nüanslar ve Senaryoların Birbirleri Arasındaki Kilit Farklar}

Her üç senaryo içerisinde tehdit olduğundan zorlama faktörünün de olduğu açıktır. Ancak bir ve üç numaralı senaryoların aksine sadece iki numaralı senaryoda Jones2, eylemini gerçekten de zorlamaya maruz kaldığı için gerçekleştirmiştir.

Joness'ün aksine Jonesı, tehdide karşı dirençlidir. Dolayısıyla o, birinci senaryoda anlatıldığı gibi değil de eylemini gerçekleştirme noktasında başka türlü yapmaya karar verirse karakterine ait bir özellik gereğince söz konusu eylemi gerçekleştirecektir.

Üç numaralı senaryoda Joness'ün başka türlü yapma olanağından mahrum olduğu kesin olsa bile $A$ eylemini kendi isteğiyle gerçekleştirip-gerçekleştirmediği varsayımları, eylemin neden gerçekleştirildiği sorusunun farklı açıklamalarını gerektirir. Bu da PAP tanımının, eylemin ancak başka türlü yapma olanağından mahrum olmadan gerçekleştirildiği durumlarda kişinin eyleminden ahlaki sorumlu 
olacağının, diğer türlüyse ahlaki sorumlu olmayacağının, ahlaki sorumlu olmak veya ahlaki sorumlu olmamak için yeter koşulu sağlayamayacağı iddiasını gerekçelendirebilmenin yolunu açacaktır. Çünkü Joness'ün $A$ eylemini gerçekleştirmek için yeterli içsel motivasyonu sağlayamadığı durumda tehdit, eş deyişle zorlama faktörü, onu söz konusu eylemi gerçekleştirmesi için motive eder. Ancak üç numaralı senaryodaki varsayım gereği Joness, A eylemini salt kendi içsel motivasyonuyla gerçekleştirmiş̧ir. Buna göre:

(1) Kişi, başka türlü yapma olanağından mahrumdur.

(2) Kişi, $A$ eylemde başka türlü yapma olanağından mahrum olarak gerçekleştirmiş olsa bile $A$ eylemini gerçekleştirdiği için ahlaki anlamda sorumludur (?). ${ }^{15}$

Üç numaralı senaryo $P A P^{\prime}$ ye karşı verilen ilk karşı-örnektir. Çünkü Joness'ün eyleminden ahlaki anlamda sorumlu olmaması için tehdit, eş deyişle zorlama faktörüne maruz kalarak eylemini gerçekleştirmesi gerekir. Joness, söz konusu eylemi başka türlü yapma olanağından mahrum olarak gerçekleştirmesine rağmen salt kendi içsel motivasyonuyla gerçekleştirmiştir.

Frankfurt bu türden senaryoların çözümlemesinin zor olduğunu kabul eder (Frankfurt, 1969: 833). Bu nedenle, üç numaralı senaryoyla bağlantılı ek bir senaryo kurgular:

Varsayalım ki(...) Black(...)Joneș'tan belli bir eylemi (A eylemini) gerçekleştirmesini istiyor olsun. Black, isteğinin yerine getirilmesi için göz ardı edilmesi olanaklı olmayan yollara başvurmaya hazır ancak gereksiz yere elini göstermekten de kaçınmayı tercih eden biri(...) Black, Jones''un ne yapacağına karar verene kadar bekler ve onun istediğinden başka ( $A$ eylemi dışında) bir şey yapmaya karar vermesini açıkça fark ettiği ana kadar ${ }^{16}$ ona herhangi bir müdahalede bulunmaz. Eğer Jones4 başka türlü yapmaya

\footnotetext{
${ }^{15} \mathrm{Bu}$ senaryoda tehdide karşı direnç gösterme faktörü ele alınmamaktadır. Frankfurt’un asıl ilgisi, tıpkı iki numaralı senaryoda üzerinde durulduğu gibi, direncin niteliksel veya niceliksel gücünü ölçmek veya göstermek değildir (Frankfurt, 1969: 834-835). Dolayısıyla Frankfurt bu senaryoya yöneltilecek olan şu türden itirazları kabul eder; Kişi, tehdit, eş deyişle zorlama faktörüne direnç gösterebilir ve bu direncin beraberinde getireceği cezayı kabul edebilir. Yine aynı biçimde, karşı konulması güç bir tehdit, eş deyişle zorlama faktörü, eylemin gerçekleştirilmesi noktasında kişinin başka türlü yapma olanağından mahrum olduğunu, kendi payına kabul etmesine neden olmuş olabilir (s. 835). Son olarak, Joness'ü ün yeterli içsel motivasyonu sağlayamadığı durumda, tıpkı iki numaralı senaryoda olduğu gibi gerçekleştirdiği $A$ eyleminden ahlaki anlamda sorumlu olmadığı ancak tehdit, eş deyişle zorlama faktörüne direnç göstermediği için ahlaki sorumlu olduğu çıkarımı yapılabilir. Ancak bu çıkarım, üç numaralı senaryonun varsayımıyla ilgisizdir. Çünkü Joness, A eylemini salt kendi içsel motivasyonuyla yani kendi isteğiyle gerçekleştirmiştir.

${ }^{16}$ Burada verilen ilk varsayıma şöyle bir soru yöneltilebilir: 'Peki, Black' in Jones'un A eylemi dışında bir şey yapmaya karar vermesini açıç̧a fark etmesi nasıl olanaklı olmaktadır?' Bu soruya verilebilecek cevap şudur: Çünkü Frankfurt zayıf bağdaşırcıdır. Klasik bağdaşırcılık gibi zayıf bağdaşırcılıkta da $C D^{\prime}$ nin doğru olduğu varsayılır. Birincil olarak $C D$, felsefi tanımı gereği, belirli bir zamanda verili olan evrenin eksiksiz bir tanımıyla birlikte doğa yasalarının eksiksiz bir açıklamasının, mantıksal olarak tüm sonraki zamanlarda evrenin eksiksiz bir tanımını gerektirdiği metafizik bir görüştür (Balaguer, 2014: 12; van Inwagen, 1975: 186).
} 
karar verirse ve Black bunu anlarsa, ona kendisinin yapmasını istediği şeyi yapmaya karar vermesi için de oldukça etkili müdahalelerde bulunur. Jones'un ilk kararları ve eğilimlerinden bağımsız olarak, gerçekleştireceği eylem, her halükârda Black'in istediği biçimde olacaktır(...) Diğer yandan, Black'in elini asla göstermesi gerekmediğini varsayalım(...) Jones4, kendi gerekçeleriyle, Black'in kendisinden gerçekleştirmesini istediği eylemi gerçekleştirmeye karar verir ve bu eylemi gerçekleştirir. Bu örnekte de açıkça görülür ki, Black kendisinin yaptığı şeyi yapması için ona müdahale etmeye hazır olmasaydı, Jones4 yaptığı şeyi zaten yapacak olduğu için eyleminden(...) ahlaki anlamda sorumlu olurdu (Frankfurt, 1969: 835-836).

Dört numaralı senaryo, $P A P^{\prime}$ a karşı öne sürülen, çözümlemesi daha açık olan esnek yapıda tasarlanmış bir diğer karşı-örnektir (Frankfurt, 1969: 836).

$\mathrm{Bu}$ senaryodaki veya karşı-örnekteki her iki varsayımın, sırasıyla aşağıdaki gibi çözümlenebilmeleri olanaklıdır:

(1) Black, Jones4'ün A eylemini gerçekleştirmesini istemektedir.

(2) Black, Jones4'ün beynine bir çip yerleştirmiştir. Bu çip, Jones4'ün başka türlü yapmaya karar verdiği anda, $A$ eyleminin başka türlü gerçekleştirileceğini bildiren sinyaller üretir. Black, çipin ürettiği sinyalleri çözen oldukça güçlü bir bilgisayar programlamıştır. ${ }^{17}$ Dolayısıyla $A$ eyleminin başka türlü yapılacağını kuşkuya yer bırakmaksızın bilecek ve Jones4'e $A$ eyleminin gerçekleştirilmesi için müdahale edebilecektir.

(3) Çip sinyal üretmemiştir.

(4) Black, Jones4'e müdahalede bulunmamıştır. Çünkü Jones4, tıpkı Black'in istediği gibi $A$ eylemini gerçekleştirmiştir.

Jones4, A eylemini, her halükârda başka türlü yapma olanağıyla gerçekleştiremez ancak bu, onun eyleminden ötürü ahlaki anlamda sorumlu olduğu gerçeğini de zayıflatmaz. Black tasarladığ 1 çip sayesinde, Jones4' ün başka türlü yapamamasını garanti altına almak için hazır beklemektedir ancak bu durum, Jones4' ün $A$ eylemini gerçekleştirmesinin bir

İkincil olarak hiçbir bilimsel teorinin veya felsefi argümanın nasıl bir evrende olunduğuna dair bir diretim bildirmediği veya bildiremeyeceği de bir malumu ilamdır. Son olaraksa zayıf bağdaşırcılık ekseninde cisimleşen $F n D D$ hatta $F V K o ̈$ 'de $C D$ ile koşut doğa yasalarına içkin hangi türde bir evrende bulunulduğu varsayımının yapılmadığına dikkat çekilmelidir. Bu gibi gerekçelerden ötürü gerek $F n D D$ nezdinde gerekse FVKö nezdinde Black, Jones'un düşüncelerini eksiksiz bir biçimde tahmin edebilir. Çünkü Black'in, moleküllerin, hücrelerin, nöronların ve nörotransmitterların neliğini veya davranışlarını eksiksiz olarak bilebilir olmasını olanaklı kılan doğa yasalarının eksiksiz bir açıklamasına sahip olması felsefi anlamda olanaklıdır (Frankfurt, 1969: 835). Özetle, (1) Black, 'başka türlü yapabilirdi' kavramına ilişkin yeterli teorik bilgiye sahipse başka türlü yapma olanağını ortadan kaldırmayı garanti altına almak için Jones'a ne türden müdahalelerde bulunabileceğinin bilgisine de sahip olmalıdır. (2) Black böyle bir yeterli teorik bilgiye sahiptir. (3) Öyleyse Black'in, başka türlü yapma olanağını ortadan kaldırmak için Jones'a müdahalelerde bulunabilmesi olanaklıdir.

17 Çip ve çipten gelen sinyalleri çözen güçlü bilgisayarın, bir tür irade manipülasyon cihazı olduğu düşünülebilir (Frankfurt, 1969: 836). 
gerekçesi olamaz. Çünkü Jonesı, başka türlü yapma olanağından mahrum olsa bile $A$ eylemini salt kendi isteğiyle gerçekleştirmiş̧tir. Dolayısıyla eylemin neden gerçekleştirildiği sorusunun cevabı, eylemin nedensel anlamda başka türlü yapma olanağından mahrum olarak gerçekleştirilmiş olmasını gerektirmez. Çünkü “(...) Herhangi bir eylemin gerçekleştirilmesinin kaçınılmaz olduğu koşullara atıfta bulunmak yeterli değildir. Kişinin, herhangi bir eylemi, bu türden koşullar olmadan da gerçekleştiriyor olmasının kaçınılmaz olduğu olası olabilir" (Frankfurt, 1969: 837). ${ }^{18} \mathrm{Bu}$ yüzden, en azından dört numaralı senaryo için şunu söylemek yerindedir: Eylemin zorla gerçekleştirildiği gerçeği, eylemin neden gerçekleştirildiğinin bir açılamasını vermez.

PAP, sezgisel olarak akla yatkındır (Copp, 2006[2003]: 251). Çünkü eylemin gerçekleştirilmesi noktasında, kişinin söz konusu eylemini gerçekleştirmekten kaçınmasını olanaksız kılan koşullar varsa bu kişinin eyleminden ötürü ahlaki anlamda sorumlu olmadığını yani kendisinin mazur görülebileceğini beyan edebilmeyi olanaklı kılar. Ancak kişinin belli bir eylemi gerçekleştirmekten kaçınamayacağ gerçeği, söz konusu eylemi gerçekleştirmiş olması için yeter bir koşul olsa da bu koşul, kişinin bu eylemi neden gerçekleştirdiğini açıklamada hiçbir rol oynamamaktadır (Frankfurt, 1969: 836).

$P A P$, sezgisel olarak akla yatkınlığını, zorlamanın ahlaki sorumluluğu dışladığı öğretisiyle olan ilişkisinden alır. Bununla birlikte, ahlaki sorumluluğun tam anlamıyla kavranması, zorlamanın çekiciliğini azaltacaktır (Frankfurt, 1969: 834).

Hangi tarafı tutup, hangi şeyi söylemeye karar verirsek verelim, zorlamanın ahlaki anlamda sorumlu olmayı dışladığı doktrininin alternatif olanaklar ilkesinin özelleştirilmiş bir uyarlaması olduğunu kabul etmiş̧ oluruz(...) Zorlayıcı bir güce maruz kalan bir kişiyi mazur gördüğümüzde, esasında başka türlü yapamadığı için onu mazur görmeyiz. Kişi, herhangi bir eylemi gerçekleştirmesini engelleyen zorlayıcı bir güce maruz kalsa bile eylemini gerçekleştirdiğinde, kendisinin ahlaki anlamda sorumlu olduğunun beyan edilebilmesini olanaklı kllar (Frankfurt, 1969: 833-834).

Dolayısıyla zorlama faktörünün devreye girdiği durumlarda ahlaki sorumluluğun yokluğunu açıklayan şey, kişinin herhangi bir gerekçeyle değil de söz konusu faktörü gerekçe göstererek hareket etmiş olmasında yatabilmektedir.

Nihayetinde kişiler, birtakım gerekçeler veya bahanelerle başka türlü yapmalarının olanaksız olduğunu söyleyerek eylemlerinden ötürü mazur görülmeyi beklerler ve

${ }^{18}$ The Dilemma Defense [İkilem Argümanı], Frankfurt'un üç ve dört numaralı karşı-örneklerinin bu alıntıdaki koşulu tam olarak sağlamadığına ilişkin literatür içindeki eleştirilere dayanak noktası teşkil eder. Bu alıntıdaki koşul nezdinde, Frankfurt'a yöneltilen kilit eleştirilerden bazıları için bkz. Kane $(1985,1999[1996])$, Widerker (1995); Ginet (1996); Goetz (2005). 
bunda da büyük ölçüde başarılı olurlar. Çünkü onlara göre, öne sürdükleri gerekçeler veya bahaneler, gerçekleştirdikleri eylemin gerçekleştirilme nedenini açıklamaktadır. Bu da eylemin etkileneni veya muhatabı olanların, bu gerekçelerin, söz konusu eylemin neden gerçekleştirilmiş olduğunun açıklanmasına hizmet ettiğini varsayıyor oldukları düşüncesiyle ilişkiseldir:

İnsanlar bizlere, başka türlü yapmalarının olanaksız olduğunu (bahaneler, gerekçeler) söylediklerinde onları yaptıklarından dolayı sık sık mazur görürüz (çünkü onlara inanıyoruz). Ancak bunun nedeni, onların bize söylediklerinin, yaptıklarını neden yaptıkları sorularının açıklamalarına hizmet ettiğini varsaymamız dolayısıyladır. Çünkü yaptığı şeyi yapmaktan kaçınamayacağını gerekçe gösteren ancak yaptığı şeyi yapma nedeninin gerekçe gösterdiği şeyden ötürü olmadığını çok iyi bilen kişinin samimiyetsiz olmadığını kabul ediyoruz (Frankfurt, 1969: 837).

Kısaca, herhangi bir eylemin gerçekleştirilmesinin olanaksız olduğu gerçeği, eylemi gerçekleştiren kişinin bu eylemi gerçekleştirmiş olması için yeter bir koşuldur (Frankfurt, 1969: 836). Ancak bu koşul, eylemin neden gerçekleştirildiğini açıklamada hiçbir rol oynamayabilir. İşte bu da $P A P^{\prime}$ nin yanlışlanabilmesi için yeterlidir.

Çünkü $P A P$, kişinin gerçekleştirmekten kaçınamayacağı eylemi için ahlaki sorumluluğu dışlar veya eylemi için bu kişinin mazur görülebileceğini varsayar.

Bununla birlikte bu varsayım, kişinin belli birtakım eylemler gerçekleştirmesine neden olacak türde ahlaki anlamda sorumlu olmaktan kaçınmasını olanaklı kılan belli birtakım koşullara atıfta bulunabilmesinin olanağını da beraberinde getirir. Haliyle $P A P^{\prime}$ nin varsayımı gereği, kişi, başka türlü yapma olanağının olmadığı koşullarda, gerçekleştirdiği eylemi için hiçbir mesuliyeti olmadığı, eş deyişle ahlaki anlamda sorumlu olmadığı yargısını öne sürebilir (Frankfurt, 1969: 836-837).

Bir diğer taraftan, $B C ̧ A$ nezdinde, kişinin belirli bir eylemi gerçekleştirmiş olması, bu eylemin nedensel anlamda belirlenmiş olduğunu doğrulayan nedensel belirleyici faktörlerin varlığına atıfta bulunur. Yani kişinin belirli bir eylemi gerçekleştirmiş olmasının nedensel anlamda belirlenmiş olması, kendisinin başka türlü yapma olanağından mahrum olduğu anlamını iletiyorsa onun söz konusu belirli bir eylemi gerçekleştirmiş olması bu eylemi, yalnızca başka türlü yapamayacağı için gerçekleştirmiş olduğu anlamına gelir (Frankfurt, 1969: 838). Hal böyleyken, böylesi bir nedensel belirlenmişlik durumunun, gerçekleştirmiş olduğu eylemi için kişinin, ahlaki anlamda sorumlu olmamasını beraberinde getirmesi doğaldır.

Tam da bu nedenle Frankfurt 'kişi ancak başka türlü yapabilseydi eyleminden ahlaki anlamda sorumlu olurdu' tanımına içkin olan $P A P^{\prime}$ nin, şu ilkeyle değiştirilmesi gerektiğini öne sürer; “(...) kişinin eylemini gerçekleştirmesinin tek nedeni başka türlü 
yapamadığı içinse kişi eyleminden ahlaki anlamda sorumlu değildir" (Frankfurt, 1969: 838-839). Böylesi bir PAP tanımı nezdinde, ahlaki sorumluluğun $C D$ ile bağdaşır olmasının olanaklı olduğu söylenebilir. Çünkü ilk tanımı nezdinde $P A P$, eylemini yaptığı gibi gerçekleştirme konusunda kişinin nedensel anlamda kararlı olması durumunda, bu kişinin gerçekleştirdiği eylemi neden gerçekleştirdiği ve neden başka türlü yapamadığı sorularının cevabını açıklamaktadır. Ancak Frankfurt’a göre, tanıma veya ilkeye getirilen bu revizyon, ahlaki sorumluluk ile $C D^{\prime}$ nin bağdaşır olduğu varsayımıyla çelişmez. Çünkü kişi, gerçekleştirdiği eylemi gerçekten de gerçekleştirmek istediği için gerçekleştirmiş olabilir (s. 839). Eş deyişle, kişinin bir eylemi gerçekleştirmesinin 'tek nedeni' gerçekten de gerçekleştirmek istemiş olması olabilir. Yani kişi, gerçekleştirdiği eylemi başka türlü yapma olanağından mahrum olarak gerçekten de gerçekleştirmek istediği için gerçekleştirmiş olabilir. Hâlbuki böylesi bir durum, söz konusu kişinin, $P A P^{\prime}$ ye göre eyleminden ahlaki anlamda sorumlu olmadığı yargısını beraberinde getirecektir. Özetle, kişinin gerçekleştirdiği eylemi, salt başka türlü yapamayacağı için gerçekleştirdiğini söylemek her halükârda doğru olamaz.

\section{Sonuç}

$F n D D^{\prime}$ de kurgulanan senaryolarda şu düşünceler iletilmeye çalışılmaktadır:

(1) Başka türlü yapma olanağından mahrum olmak ÖI'yi dışlamadığı gibi ahlaki sorumluluğu da dişlamaz.

(2) Eylemin gerçekleştirilmesi noktasında tehdit, eş deyişle zorlama faktörünü gerekçe göstererek harekete geçmek ÖI'yi dışlar.

(3) Eylemin gerçekleştirilmesi noktasında tehdit, eş deyişle zorlama faktörünü gerekçe göstererek harekete geçmek başka türlü yapma olanağından mahrum olmakla aynı anlama gelmez.

Öte yandan, başka türlü yapma olanağının dışlanması, kapsayıcı (hipernim) bir kavram olan ÖI kavramının eksiksiz bir tanımda içkin olmadığını gerekçelendirebilir.

Bu durumda, Frankfurt'un argümanları baz alındığında, bu metnin önceki satırlarında verilen Campbell'a ait zayıf bağdaşırcılık tanımının aşağıdaki biçimde ufak bir düzeltmeyi gerektirdiği söylenebilir:

(1) Ahlaki sorumluluk, alternatif eylem olanaklarını gerektirmediği gibi en azından başka türlü yapma olanağının söz konusu olduğu bir Öİ türünü de gerektirmez. 
(2) Ahlaki sorumluluk ve ahlaki sorumluluk için gerekli olan başka türlü yapma olanağının söz konusu olmadığı bir ÖI türü, $C D$ ile bağdaşır.

\section{Kaynakça}

Austin, J. L. (1979). “Ifs and Cans." J. O. Urmson and G. J. Warnock (Der.), Philosophical Papers (3rd Edition) içinde (s. 205-232). New York, NY: Oxford University Press. DOI: 10.1093/019283021x.001.0001

Balaguer, M. (2014). Free Will. Cambridge, MA: The Massachusetts Institute of Technology (MIT) Press. DOI: 10.7551/mitpress/9996.001.0001

Campbell, J. K. (1997). "A Compatibilist Theory of Alternate Possibilities." Philosophical Studies: An International Journal for Philosophy in the Analytic Tradition, 88(3): 319-330.

Campbell, J. K. (2016). “The Consequence Argument.” Kevin Timpe, Meghan Griffith and Neil Levy (Der.), The Routledge Companion to Free Will içinde (s. 151-165). Oxfordshire, OXF: Routledge and Taylor \& Francis Group. DOI: 10.4324/9781317422266-27

Copp, D. (1997). "Defending the Principle of Alternate Possibilities: Blameworthiness and Moral Responsibility." Noûs, 31(4): 441-456. DOI: 10.1111/0029-4624.00055

Copp, D. (2006). "'Ought' Implies 'Can', Blameworthiness, and the Principle of Alternate Possibilities." David Widerker and Michael McKenna (Der.), Moral Responsibility and Alternative Possibilities: Essays on the Importance of Alternative Possibilities içinde (s. 251-299). Aldershot, HA: Ashgate Publishing Limited.

Descartes, R. (2013). Meditations on First Philosophy. Der. Andrew Bailey. Çev. Ian Johnston. Peterborough: Broadview Press.

Fischer, J. M. (2005). “General Introduction." John Martin Fischer (Der.), Free Will: Critical Concepts in Philosophy: Concepts and Challenges (Vol 1) içinde (s. XXIIIXXX). Oxfordshire, OXF: Routledge and Taylor \& Francis Group.

Fischer, J. M. (2010). "The Frankfurt Cases: The Moral of the Stories." The Philosophical Review, 119(3): 315-336. DOI: 10.1215/00318108-2010-002

Fischer, J. M. (2012). "The Frankfurt-Style Cases: Philosophical Lightning Rods." Reprints and Working Papers of the Centre for Advanced Study in Bioethics, 46: 1-12.

Frankfurt, H. G. (1969). “Alternate Possibilities and Moral Responsibility.” The Journal of Philosophy, 66(23): 829-839. DOI: 10.2307/2023833

Gettier, E. L. (1963). “Is Justified True Belief Knowledge?” Analysis, 23(6): 121-123.

DOI: 10.1093/analys/23.6.121 
Ginet, C. (1996). “In Defense of the Principle of Alternative Possibilities: Why I Don't Find Frankfurt's Argument Convincing." Noûs: Philosophical Perspectives, Metaphysics, 10: 403-417. DOI: 10.2307/2216254

Goetz, S. (2005). "Frankfurt-Style Counter-examples and Begging the Question." Midwest Studies in Philosophy, 29: 83-105. DOI: 10.2307/2214275

Gustafsson, J. E. (2017). "A Strengthening of the Consequence Argument for Incompatibilism." Chris Daly and David Liggins (Der.), Analysis, 77(4): 705-715. DOI: $10.1093 /$ analys/anx103

Harrison, G. K. (2006). “Frankfurt-Style Cases and Improbable Alternate Possibilities.” Philosophical Studies: An International Journal for Philosophy in the Analytic Tradition, 130(2): 399-406. DOI: 10.1007/s11098-004-5753-5

Kane, R. (1985). Free Will and Values. Albany, NY: State University of New York (SUNY) Press.

Kane, R. (1999). The Significance of Free Will (2nd Edition). New York, NY: Oxford University Press. DOI: 10.1093/0195126564.001.0001

Kenny, A. (1987). Descartes: A Study of His Philosophy (2nd Edition). New York, NY: Garland Publishing, Inc.

List, C. (2019). "What's Wrong with the Consequence Argument: A Compatibilist Libertarian Response." Proceedings of the Aristotelian Society, 119(3): 253-274. DOI: 10.1093/arisoc/aoz018

Locke, J. (1999). An Essay Concerning Human Understanding. State College, PA: The Pennsylvania State University.

McKenna, M. (2010). "Whose Argumentative Burden, Which Incompatibilist Arguments? -Getting the Dialectic Right." Australasian Journal of Philosophy, 88(3): 429-443. DOI: 10.1080/00048400903233811

Nietzsche, F. (2007). "Twilight of the Idols." Çev. Judith Norman. Aaron Ridley and Judith Norman (Der.), The Anti-Christ, Ecce Homo, Twilight of the Idols, and Other Writings (4th Edition) içinde (s. 153-230). Cambridge, MA: Cambridge University Press.

Plato (1997). "Apology." Çev. G. M. A. Grube. John Madison Cooper and Douglas S. Hutchinson (Der.), Plato: Complete Works içinde (s. 17-36). Indianapolis, IN: Hackett Publishing Company, Inc.

Timpe, K. (2013). Free Will: Sourcehood and its Alternatives (2nd Edition). New York, NY: Bloomsbury Publishing Plc. 
Van Inwagen, P. (1975). “The Incompatibility of Free Will and Determinism.” Philosophical Studies: An International Journal for Philosophy in the Analytic Tradition, 27(3): 185-199. DOI: 10.1007/bf01624156

Van Inwagen, P. (1983). An Essay on Free Will. New York, NY: Oxford University Press. DOI: $10.2307 / 2214275$

Van Inwagen, P. (1989). "When is the Will Free?" Noûs: Philosophical Perspectives, Philosophy of Mind and Action Theory, 3: 399-422. DOI: 10.2307/2214275

Van Inwagen, P. (1999). "Moral Responsibility, Determinism, and the Ability to Do Otherwise." J. Angelo Corlett (Der.), The Journal of Ethics, 3(4): 341-350.

Van Inwagen, P. (2000). "Free Will Remains a Mystery." Nô̂s: Philosophical Perspectives, Action and Freedom, 14: 1-19. DOI: 10.1111/0029-4624.34.s14.1

Vihvelin, K. (2013). Causes, Laws, and Free Will: Why Determinism Doesn't Matter. New York, NY: Oxford University Press. DOI: 10.1093/acprof:oso/978019975185.001.0001

Vihvelin, K. (2018). “Arguments for Incompatibilism.” Edward N. Zalta (Der.), The Stanford Encyclopedia of Philosophy (Fall 2018 Edition) içinde. Alındiğı URL: https://plato.stanford.edu/archives/fall2018/entries/incompatibilism-arguments/

Widerker, D. (1995). “Libertarianism and Frankfurt's Attack on the Principle of Alternative Possibilities." The Philosophical Review, 104(2): 247-261. DOI: 10.2307/2185979 


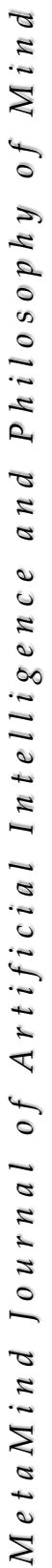

